\title{
BMJ Open Factors associated with going outdoors frequently: a cross-sectional study among Swiss community-dwelling older adults
}

\author{
Julia Spaltenstein (D) , ${ }^{1}$ Christophe Bula, ${ }^{1}$ Brigitte Santos-Eggimann, ${ }^{2}$ Helene Krief, ${ }^{1}$ \\ Laurence Seematter-Bagnoud ${ }^{1,2}$
}

To cite: Spaltenstein J, Bula C, Santos-Eggimann B, et al. Factors associated with going outdoors frequently: a cross-sectional study among Swiss community-dwelling older adults. BMJ Open 2020;10:e034248. doi:10.1136/ bmjopen-2019-034248

- Prepublication history and additional material for this paper are available online. To view these files, please visit the journal online ().

Received 11 September 2019 Revised 17 March 2020 Accepted 18 June 2020

\section{Check for updates}

(C) Author(s) (or their employer(s)) 2020. Re-use permitted under CC BY-NC. No commercial re-use. See rights and permissions. Published by BMJ.

${ }^{1}$ Service of Geriatric Medicine and Geriatric Rehabilitation, University Hospital of Lausanne, Lausanne, Switzerland

${ }^{2}$ Center for Primary Care and Public Health (Unisanté) University of Lausanne, Lausanne, Switzerland

Correspondence to Dr Julia Spaltenstein; julia.spaltenstein@unil.ch

\section{ABSTRACT}

Objective This study examines potential risk and protective factors associated with going outdoors frequently among older persons, and whether these factors vary according to physical limitations.

Design Cross-sectional analysis.

Setting and participants Community-dwelling participants of the Lausanne cohort Lc65+ in 2016, aged 68-82 years $(n=3419)$.

Methods Associations between going outdoors frequently and physical limitations, sociodemographic, health, psychological and social variables were examined using logistic regression models. Subgroup analyses were performed according to the severity of physical limitations. Main outcome measures 'Going outdoors frequently' was defined as going out $\geq 5$ days/week and not spending most of the time sitting or lying down.

Results Three in four (73.9\%) participants reported going outdoors frequently. Limitations in climbing stairs (adjusted OR (AdjOR) $0.61,95 \% \mathrm{Cl} 0.47$ to 0.80 ) and walking (AdjOR $0.24,95 \% \mathrm{Cl} 0.18$ to 0.31 ), as well as depressive symptoms (Adj0R 0.58, 95\% Cl 0.47 to 0.70 ), dyspnoea (AdjOR 0.60, 95\% Cl 0.48 to 0.75), age (AdjOR $0.73,95 \% \mathrm{Cl} 0.59$ to 0.92 ) and fear of falling (AdjoR 0.75 , $95 \% \mathrm{Cl} 0.62$ to 0.91 ) reduced the odds of going outdoors frequently. In contrast, living alone (AdjOR $1.30,95 \% \mathrm{Cl}$ 1.08 to 1.56 ), reporting a dense (AdjOR $1.57,95 \% \mathrm{Cl} 1.26$ to 1.96 ) and a high-quality (AdjOR $1.28,95 \% \mathrm{Cl} 1.06$ to 1.53) social network increased the odds of going outdoors frequently. Among participants with severe limitations, $44.6 \%$ still went outdoors frequently. Among this subgroup, a new emotional relationship (AdjOR 2.52, 95\% Cl 1.18 to 5.38) was associated with going outdoors, whereas cognitive complaints (AdjOR $0.66,95 \% \mathrm{Cl} 0.47$ to 0.93 ), urinary incontinence (AdjOR $0.67,95 \% \mathrm{Cl} 0.46$ to 0.97 ), dyspnea (AdjOR:0.67, 95\%Cl:0.48-0.93), and depressive symptoms (AdjOR 0.67, $95 \% \mathrm{Cl} 0.48$ to 0.93 ) lowered the odds of going outdoors.

Conclusion Physical limitations are associated with decreased odds of going outdoors frequently. However, social characteristics appear to mitigate this association, even among older persons with severe limitations. Further studies are needed to determine causality and help guide interventions to promote going outdoors as an important component of active ageing.
Strengths and limitations of this study

- This study is based on a large sample, representative of community-dwelling older men and women.

- Data from the Lausanne cohort Lc65+ study include detailed information on the type of physical limitations, as well as an extensive set of covariates relevant to outdoor mobility, including different components of social network.

- The study's cross-sectional design does not allow to assess causality.

\section{INTRODUCTION}

Time spent out-of-home is associated with higher quality of life, increased physical activity as well as improved cognitive function. ${ }^{12}$ In frail older adults, going outdoors at least four times a week is linked to a higher likelihood of remaining independent in activities of daily living (ADLs) and living at home over a 20-month follow-up period. ${ }^{3}$ Furthermore, encouraging going out of one's home is of central interest to promote active ageing, a concept that has been defined by WHO as the ability to continue participating in social, economic, cultural, spiritual and civic affairs. ${ }^{45}$

Studies have highlighted that time spent out-of-home is impacted by environmental barriers, by factors related to physical ability, such as walking speed, as well as by health factors such as cognitive and psychological status, pain, urinary incontinence and hearing impairment. ${ }^{6-9}$ Falls and fear of falling have also been shown to impact time spent out of home. ${ }^{1011}$

Physical limitations are mentioned as a leading cause of decreased time spent outof-home. ${ }^{12}$ About 20\%-30\% of communitydwelling older adults in the USA and the UK report physical limitations, ${ }^{13} 14$ making it important to investigate in more details the 
interplay between these limitations and going outdoors in order to efficiently promote outdoor mobility. Indeed, some studies have shown that the presence of physical limitations modifies which factors are associated with time spent out-of-home. ${ }^{78}$ For instance, environmental barriers affect time spent out-of-home only among older people with reduced lower extremity performance. ${ }^{8}$ In contrast, hearing impairment appears associated with homebound status, defined as going out of one's home at most once a week, only among older persons without physical limitations. ${ }^{7}$ However, these two studies only considered few potential confounders.

Only a small number of protective factors for outdoor mobility have been highlighted. For instance, an ongoing cohort study is investigating whether social network could act as a protective factor, ${ }^{15}$ a hypothesis further suggested by a previous literature review that identified a positive association between support from friends or family, and mobility (ie, the ability to move oneself within the community environment). ${ }^{16}$ Previous studies that looked at the positive association between various health and social factors and time spent out-of-home are scarce. Furthermore, information from these studies remains lacunar, as most involved a limited number of subjects ${ }^{6}$ or considered few adjustment variables. ${ }^{7817}$ Finally, most previous studies focused on the homebound status. ${ }^{18-22}$

Considering the current interest for active ageing, this study focuses on factors associated with going outdoors frequently. Using data from the Lausanne cohort Lc65+ study, the present work investigates the relationships between older adults' health-related factors (including physical limitations), their social network and going outdoors frequently. The first objective was to examine in more details how different self-reported physical limitations were associated with going outdoors frequently. The hypothesis was that some physical limitations (eg, related to lower rather than upper limbs performance) would be more likely to have a significant negative association with going outdoors frequently. Based on previous literature findings and hypothesised associations between individual characteristics and outdoor mobility, another objective was to identify potential risk factors (insecurity in the street, mood disorder, fear of falling, cognitive complaints, urinary incontinence, falls, pain, dyspnoea, vertigo), as well as protective factors (strong social network, optimism) for going outdoors frequently, while accounting for physical limitations (figure 1) and their severity.

\section{METHODS}

\section{Data collection}

The Lausanne cohort Lc65+ follows three random samples of community-dwelling individuals enrolled when aged 65-70 years in year 2004 (wave 1, birth year 1934-1938), 2009 (wave 2, birth year 1939-1943) and 2014 (wave 3, birth year 1944-1948). Participants receive a yearly questionnaire and undertake a clinical examination every 3 years. ${ }^{23}$

\section{Study population}

Analyses for this study included individuals from the three cohort waves who participated in the 2016 data collection $(\mathrm{n}=3509)$. Participants with missing data about the frequency of going outdoors $(n=13)$, those living in a nursing home $(\mathrm{n}=10)$ and those with significant cognitive impairment-defined as a Mini-Mental Status Examination (MMSE) score $<18$ on their last assessment (in year 2014, 2015 and 2016, respectively, n=9)—were excluded. In addition, participants whose questionnaires were filled

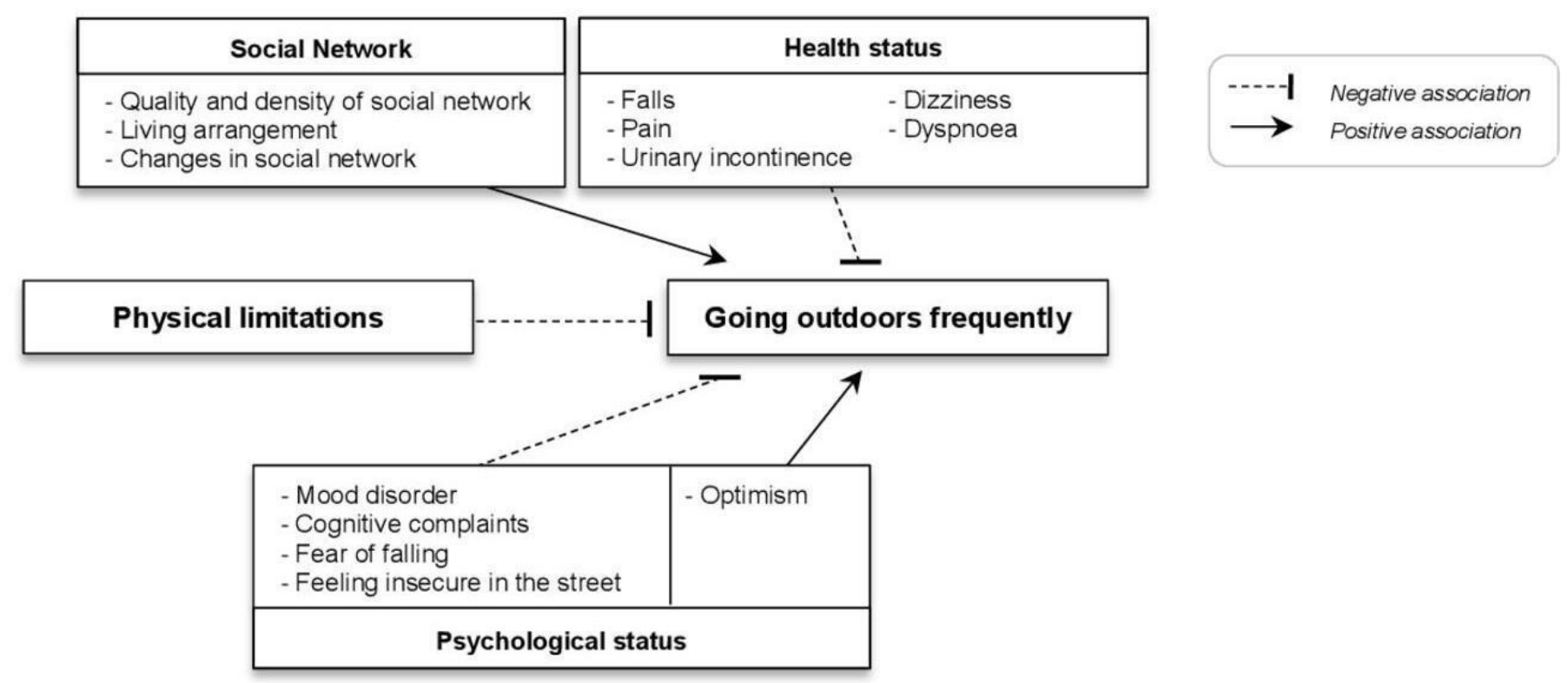

Figure 1 Conceptual framework of the hypothesised relationships between physical limitations, psychosocial and health factors and going outdoors frequently. 
in by proxy $(\mathrm{n}=58)$ were also excluded, leaving a final sample of 3419 subjects.

\section{Measures}

Information on all variables was extracted from the selfreported baseline questionnaire (for sociodemographic variables) and the 2016 yearly questionnaire (for outdoor mobility status, physical limitations, health status, psychological status and social network).

\section{Definition of the outcome}

Participants who met the 'going outdoors frequently' criterion were defined as those who reported going outside 5-7 days per week over the previous 12-month period (versus answering going outdoors: 'three to four times a week'; or 'once to twice a week' or "I almost never leave my home"). To improve the specificity of the outcome measure, participants who reported spending most of the time sitting or lying down and not moving much were categorised as not meeting the outcome's criteria (versus answering: "I often walk but I avoid climbing stairs, or carrying loads"; "I often walk, climb stairs, and I carry light loads" or "I am physically active and I often carry heavy loads").

\section{Physical limitations}

Physical limitations were assessed based on self-reported difficulty or inability in eight activities: 1) walking $100 \mathrm{~m}$ : 'limitations with walking'; 2) standing up from a chair after staying seated for a long time: 'limitations with standing up from a chair'; 3) climbing up one flight of stairs without stopping: 'limitations with climbing stairs'; 4) bending forward, kneeling or squatting: 'limitations with bending'; 5) reaching for an object above shoulder level: 'limitations with reaching above shoulder level; 6) pulling or pushing large objects: 'limitations with pushing objects'; 7) lifting or carrying over 5 kilos: 'limitations with carrying' and 8) catching a small object with the fingertips: 'limitations with catching small objects.

\section{Covariates}

\section{Sociodemographic}

Information was collected at enrolment regarding year of birth ('age groups' calculated in the year 2016: younger (67-72 years), middle (73-77 years), older (78-82 years) ), 'sex' and education ('higher education' defined as having finished high school, or having a professional or university diploma).

\section{Health status}

Information on the following variables was self-reported: history of 'falls' in the past 12 months; 'comorbidities' number of conditions diagnosed or under treatment over the last 12 months (having either none, or one, or two and more conditions among the following: high blood pressure, high cholesterol level, coronary disease, heart failure, valve or myocardial disease, stroke, diabetes, chronic pulmonary disease, asthma, osteoporosis, bone fracture, arthritis or arthrosis, cancer, stomach or duodenal ulcers, depression, Parkinson's disease, Alzheimer's disease, HIV infection, one or more other chronic diseases); being bothered by the following symptoms since at least 6 months: 'pain' in the joints or back or chest; dizziness or 'vertigo'; breathlessness or trouble breathing, labelled as 'dyspnoea'; involuntary urinary loss, labelled as 'urinary incontinence'.

\section{Psychological status}

The following variables were selected: 'insecurity in the street' (defined as feeling uneasy or unsatisfied regarding one's own security in the street); reporting a lot or a little of 'fear of falling'; 'depressive feelings' (defined as reporting in the last 4 weeks a) feeling sad, depressed or discouraged, and/or b) feeling a lack of pleasure or interest in usual activities); 'optimism': answering that one's own quality of life in a year will be better or the same but not worse as it is now; 'cognitive complaints' (ie, feeling bothered often or very often by at least one of the following: a) remembering conversations; b) learning to use new technology; c) resuming a reading after being interrupted; d) remembering the name of people; e) concentrating on a task; f) explaining a show that was just watched; g) needing to be reminded of things to do; $h$ ) calculating the amount of change; i) needing to think longer in order to do things correctly).

\section{Social network}

Self-reported information on the following variables was considered: 'living alone'; 'death of the spouse or partner' within the past 12 months; having experienced a 'new emotional relationship'; 'dense social network' (defined as the highest quartile of the 6-item Lubben's Social Network Scale) and 'high-quality social network' (ie, answers 'very often' or 'always' to all three questions: a) how often can you count on someone for help; b) how often can you count on someone to share personal matters and c) how often can you count on someone you love and for whom you matter).

\section{Statistical analyses \\ Selection of physical limitations}

In a first step, the specific association between each of the eight physical limitations and the 'going outdoors frequently' outcome was determined using bivariate logistic regression. The physical limitations that were significantly associated with the outcome were then entered altogether in a multivariate logistic regression, without adjusting for any covariate. Subsequent analyses only used the physical limitation independently associated with the outcome. These physical limitations were also stratified into mild versus severe limitations based on the strength of their association with the outcome and their distribution among the study population.

\section{Bivariate analyses}

The characteristics of participants who did or did not go outdoors frequently were compared in bivariate analyses, using unadjusted logistic regression analyses. A similar 
analysis was performed in the subgroups of participants with mild and severe physical limitations, respectively.

\section{Multivariate analyses}

Multivariate analyses were performed similarly in the total population and in the two subgroups with mild and severe physical limitations, using as candidate variables those identified in bivariate analyses. Although 'living alone' was not significantly associated with the outcome in bivariate analysis, this variable was forced in the multivariate models because of its hypothesised role. Interactions between physical limitations and selected covariates were tested in the total sample analysis. Final models were run again after excluding variables that did not remain significantly associated with the outcome. The validity of all models was examined using the Hosmer-Lemeshow goodness-of-fit test.

Statistical significance was set at a $p$ value of $<0.05$. All analyses were performed using Stat V.15.1 (StataCorp).

\section{Sensitivity analysis}

Information on MMSE was lacking in 374 participants $(10.9 \%)$ who were unable to attend the in-person clinical assessment or refused to perform the MMSE. A sensitivity analysis excluding individuals with missing MMSE information was therefore carried out.

\section{Patient and public involvement statement}

Participants were not involved in the design and conduct of the Lc65+ study. The results of the Lc65+ data analyses are summarised and presented in a simplified way in the newsletter that the participants receive each year.

\section{RESULTS}

\section{Population characteristics}

The total sample included 3419 individuals aged 68-82 years, with each 5-year age group defined by cohort wave representing about a third of the sample. More than half $(59.5 \%)$ were female and $44 \%$ reported a higher education.

In total, 2637 participants reported going outdoors 5-7 times a week. However, 109 of them $(4.1 \%)$ also reported spending most of the time sitting or lying down and not moving much, and thus did not meet the outcome criteria. This left a total of 2528 participants (73.9\% of the total sample) that reported the outcome 'going outdoors frequently'.

Individuals reporting going outdoors frequently were younger, more optimistic and achieved a higher education than those who did not report going outdoors frequently (table 1). Participants who went outdoors frequently also reported fewer health conditions and a stronger social network (higher density and higher quality social network, and more frequent new emotional relationship).

\section{Physical limitations}

Among the total population, limitations with bending was the most frequent physical limitation $(55.1 \%)$, followed by limitations with carrying $(38.7 \%)$, with standing up from a chair $(36.9 \%)$, and with pushing objects $(32.4 \%)$. Limitations that were the least frequently reported were limitations with climbing stairs (15.3\%), and with walking $(12.6 \%)$. In bivariate analysis, each of the eight physical limitations were significantly less present among participants who went outdoors frequently (all $\mathrm{p}<0.001$ ) (online supplementary table 1 ).

In the multivariate logistic regression model that included all eight physical limitations, four limitations did not remain associated with the outcome: limitations with a) pushing objects (adjusted OR (AdjOR) 1.02, 95\% CI 0.80 to 1.28); b) catching small objects (AdjOR $0.93,95 \%$ CI 0.74 to 1.17$)$; c) reaching above shoulder level (AdjOR 0.85, 95\% CI 0.68 to 1.08 ); d) standing up from a chair (AdjOR $0.85,95 \%$ CI 0.70 to 1.03 ). In contrast, four limitations remained independently associated with significantly lower odds of going outdoors frequently (figure 2). Limitations with a) walking (AdjOR $0.23,95 \%$ CI 0.18 to 0.30 ); b) climbing stairs (AdjOR 0.54, 95\% CI 0.42 to 0.70 ); c) bending (AdjOR 0.73 , 95\% CI 0.60 to 0.88 ) and d) carrying (AdjOR $0.75,95 \%$ CI 0.62 to $0.91)$. Overall, $65.8 \%$ of the participants within the total population reported at least one of these four limitations, a proportion that was only slightly but significantly lower (60.5\%; $\mathrm{p}<0.001)$ among the subgroup of participants going outdoors frequently.

A hierarchy was apparent within these four limitations as participants reporting only one limitation most often had limitations with bending (70.4\%), whereas those with two limitations, most often reported limitations with bending and carrying $(81.7 \%)$, and those with three limitations most often reported limitations with bending, carrying and climbing stairs (52.7\%). Based on these results, participants reporting limitations with bending and/or carrying but not with climbing stairs and walking ( $44.8 \%$ of the total sample) were considered as having mild physical limitations, whereas those reporting limitations with stairs and/or walking (19.4\% of the total sample) were considered as having severe physical limitations in further analyses. This classification was further supported by results from bivariate analyses that showed stronger associations with going outdoors frequently for severe compared with mild physical limitations.

In subgroups analyses, $77.8 \%$ of the participants with mild limitations reported going outdoors frequently, vs $44.6 \%$ of those with severe limitations. These latter were older, had a worse overall health and psychological status as well as a weaker social network than those with mild limitations (online supplementary table 2).

\section{Results from multivariate analyses}

In the total population (table 2), results from multivariate analysis showed that going outdoors frequently was less likely in participants who reported limitations with walking (AdjOR 0.24, 95\% CI 0.18 to 0.31 ) and limitations with climbing stairs (AdjOR 0.61, 95\% CI 0.47 to 0.80 ), as well as those within the older age group (78-82 years, 
Table 1 Characteristics of the study population and comparisons between participants going outdoors frequently or not

Going outdoors

frequently?

\begin{tabular}{|c|c|c|c|c|c|c|}
\hline & & \multirow[b]{2}{*}{$\begin{array}{l}\text { Total population } \\
(\mathrm{N}=3419)(100 \%)\end{array}$} & \multicolumn{2}{|l|}{ frequently? } & \multirow[b]{2}{*}{$\begin{array}{l}\text { Unadjusted OR } \\
(95 \% \mathrm{Cl})\end{array}$} & \multirow[b]{2}{*}{$P$ value } \\
\hline \multicolumn{2}{|c|}{ Characteristics (mean) (\%) } & & $\begin{array}{l}\text { Yes }(\mathrm{N}=2528 \\
73.9 \%)\end{array}$ & $\begin{array}{l}\text { No }(\mathrm{N}=891 ; \\
26.1 \%)\end{array}$ & & \\
\hline \multirow{4}{*}{ Sociodemographic } & $\begin{array}{l}\text { Age groups by cohort } \\
\text { wave }(\%)\end{array}$ & & & & & \\
\hline & $78-82$ years (wave 1 ) & 34.6 & 24.1 & 26.8 & (ref) & $<0.001$ \\
\hline & $68-72$ years (wave 3 ) & 35.5 & 43.1 & 41.1 & 0.57 (0.48 to 0.69$)$ & \\
\hline & Higher education (\%) & 44.0 & 47.1 & 35.1 & 1.65 (1.41 to 1.93$)$ & $<0.001$ \\
\hline \multirow[t]{6}{*}{ Health } & Comorbidities (\%) & & & & & \\
\hline & None & 23.8 & 26.0 & 17.6 & (ref) & $<0.001$ \\
\hline & Dyspnoea (\%) & 17.2 & 13.0 & 29.1 & $0.36(0.30$ to 0.44$)$ & $<0.001$ \\
\hline & Pain (\%) & 61.9 & 58.2 & 72.2 & $0.54(0.45$ to 0.63$)$ & $<0.001$ \\
\hline & Urinary incontinence (\%) & 14.4 & 12.3 & 20.3 & $0.55(0.45$ to 0.68$)$ & $<0.001$ \\
\hline & Falls (\%) & 19.0 & 17.2 & 24.4 & $0.64(0.53$ to 0.77$)$ & $<0.001$ \\
\hline \multirow[t]{4}{*}{ Psychological } & Depressive feelings (\%) & 25.6 & 20.5 & 40.2 & $0.38(0.32$ to 0.45$)$ & $<0.001$ \\
\hline & Insecurity in the street (\%) & 37.0 & 33.7 & 46.7 & $0.58(0.49$ to 0.68$)$ & $<0.001$ \\
\hline & Fear of falling (\%) & 50.6 & 45.1 & 65.3 & 0.44 (0.38 to 0.52$)$ & $<0.001$ \\
\hline & $\begin{array}{l}\text { Optimism, quality of life in } \\
\text { a year }(\%)\end{array}$ & & & & & \\
\hline \multirow{2}{*}{ Social network } & $\begin{array}{l}\text { New emotional } \\
\text { relationship (\%) }\end{array}$ & 7.2 & 7.8 & 5.5 & 1.45 (1.05 to 2.01$)$ & 0.025 \\
\hline & $\begin{array}{l}\text { Death of the spouse or } \\
\text { partner }(\%)\end{array}$ & 1.56 & 1.47 & 1.81 & $0.81(0.45$ to 1.46$)$ & 0.485 \\
\hline
\end{tabular}

Refer to 'Methods' section for detailed definition of the characteristics.

ORs and $p$ values from unadjusted logistic regression analysis.

AdjOR $0.73,95 \%$ CI 0.59 to 0.92$)$, those reporting depressive feelings (AdjOR 0.58, 95\% CI 0.47 to 0.70 ), dyspnoea (AdjOR $0.60,95 \%$ CI 0.48 to 0.75 ) and fear of falling (AdjOR $0.75,95 \%$ CI 0.62 to 0.91 ). In contrast, those living alone (AdjOR 1.30, 95\% CI 1.08 to 1.56), reporting a dense (AdjOR 1.57, 95\% CI 1.26 to 1.96 ) or a highquality social network (AdjOR 1.28, 95\% CI 1.06 to 1.53 ) had increased odds of going outdoors frequently. None of the interactions between the physical limitations and the different covariates achieved statistical significance.

In subgroup analyses, a different set of variables was associated with going outdoors frequently in participants with mild versus severe physical limitations. Among the former, a significant association with higher education (AdjOR $1.30,95 \%$ CI 1.00 to 1.70 ) appeared, whereas older age and a high-quality social network were no longer significantly associated with going outdoors frequently. Among participants with severe physical limitations, the odds of going outdoors frequently were significantly decreased when reporting dyspnoea (AdjOR $0.67,95 \%$ CI 0.48 to 0.93 ), urinary incontinence (AdjOR 0.67, 95\% CI 0.46 to 0.97 ), depressive feelings (AdjOR 0.67, 95\% CI 0.48 to 0.93 ) or cognitive complaints (AdjOR 0.66, 95\% CI 0.47 to 0.93). In contrast, having a new emotional relationship was associated 


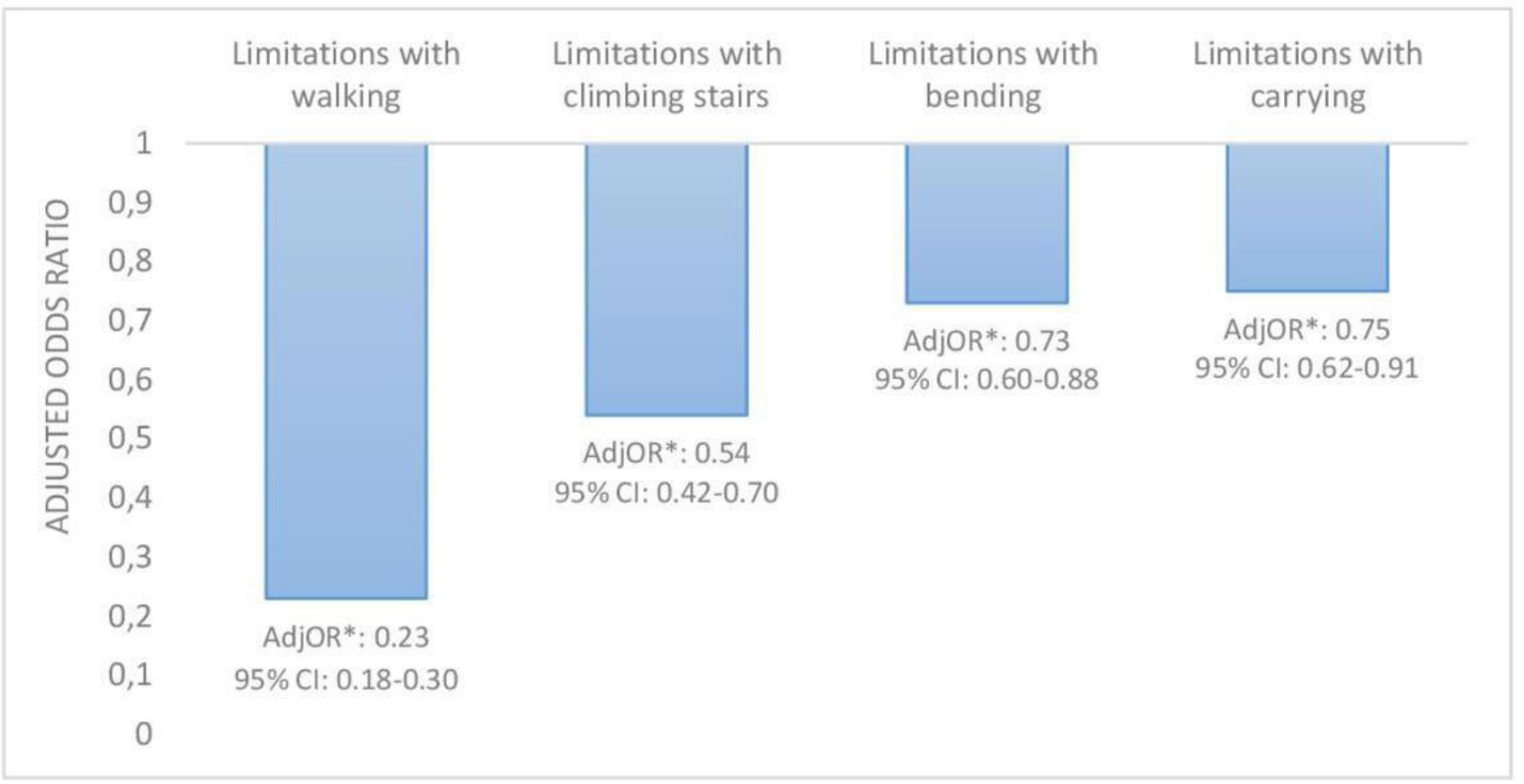

Figure 2 Mutually adjusted effect (OR) of the four types of physical limitations significantly associated with going outdoors frequently.

with more than twofold higher odds of reporting going outdoors frequently (AdjOR 2.52, 95\% CI 1.18 to 5.38).

All three multivariate models presented a good fit of the data (1-roc values from Hosmer-Lemeshow goodness-of-fit test for model 1: 0.74, for model 2: 0.63 and for model 3: $0.62)$.

\section{Sensitivity analyses}

In the total population, similar results were obtained in the sensitivity analyses that excluded participants with missing MMSE. In the subgroup analysis among patients with mild physical limitations, living alone and having a

Table 2 Results from multivariate logistic regression analyses that investigated associations of physical limitations, sociodemographic, health, psychological and social network characteristics with 'going outdoors frequently' outcome

\begin{tabular}{|c|c|c|c|c|c|c|c|}
\hline \multirow[b]{2}{*}{ Characteristics } & & \multicolumn{2}{|l|}{$\begin{array}{l}\text { Total sample } \\
(n=3171)\end{array}$} & \multicolumn{2}{|c|}{$\begin{array}{l}\text { Participants with mild* } \\
\text { limitations }(n=1446)\end{array}$} & \multicolumn{2}{|c|}{$\begin{array}{l}\text { Participants with severe } \\
\text { limitations }(n=627)\end{array}$} \\
\hline & & $\begin{array}{l}\text { Adjusted OR } \\
(95 \% \mathrm{Cl})\end{array}$ & $P$ value & $\begin{array}{l}\text { Adjusted OR } \\
(95 \% \mathrm{Cl})\end{array}$ & $P$ value & $\begin{array}{l}\text { Adjusted OR } \\
(95 \% \mathrm{Cl})\end{array}$ & $P$ value \\
\hline Physical limitations & Limitations with climbing stairs & 0.61 (0.47 to 0.80$)$ & $<0.001$ & - & - & - & - \\
\hline \multirow[t]{3}{*}{ Sociodemographic } & Age group & & & & & & \\
\hline & 78-82 years (wave 1) & 0.73 (0.59 to 0.92$)$ & 0.006 & - & - & - & - \\
\hline & Higher education & - & - & 1.30 (1.00 to 1.70$)$ & 0.049 & - & - \\
\hline \multirow[t]{2}{*}{ Health } & Dyspnoea & 0.60 (0.48 to 0.75$)$ & $<0.001$ & 0.66 (0.47 to 0.92) & 0.014 & $0.67(0.48$ to 0.93$)$ & 0.018 \\
\hline & Urinary incontinence & - & - & - & - & 0.67 (0.46 to 0.97$)$ & 0.033 \\
\hline \multirow[t]{4}{*}{ Social network } & Living alone & 1.30 (1.08 to 1.56$)$ & 0.006 & 1.34 (1.03 to 1.75$)$ & 0.031 & - & - \\
\hline & Dense social network & 1.57 (1.26 to 1.96$)$ & $<0.001$ & $1.40(1.02$ to 1.91$)$ & 0.037 & - & - \\
\hline & High-quality social network & 1.28 (1.06 to 1.53$)$ & 0.009 & - & - & - & - \\
\hline & New emotional relationship & - & - & - & - & 2.52 (1.18 to 5.38$)$ & 0.017 \\
\hline
\end{tabular}

Refer to 'Methods' section for a detailed definition of the characteristics.

The following variables did not remain significantly associated with the 'going outdoors frequently' outcome in any of the three multivariate models and are not shown in Table 2: limitations with bending, limitations with carrying, sex, comorbidity, vertigo, pain, falls, insecurity in the street, optimism, death of the spouse or partner.

*Mild physical limitations: limitations in bending and/or carrying.

†Severe physical limitations: limitations in walking and/or climbing stairs. 
dense social network were no longer significantly associated with going outdoors frequently, although their ORs were similar to those presented in table 2. Results were essentially similar in the subgroup with severe limitations, except for urinary incontinence that was no longer significant but also had similar OR.

\section{DISCUSSION}

In the present study, about three-quarters of communitydwelling adults aged 68-82 years reported going outdoors frequently despite the presence of physical limitations in a substantial proportion of them. Among individuals with severe limitations, still almost half of them did go outdoors frequently. Limitations with walking and climbing stairs considerably decreased odds of reporting going outdoors frequently but so did other variables such as depressive feelings and fear of falling. On the contrary, social variables increased those odds and so did the fact of living alone. Among individuals with severe limitations, cognitive complaints and urinary incontinence became significant in decreasing odds of going outdoors frequently.

This study provides a unique detailed picture of the interplay between physical limitations, an extensive set of health and social covariates, and the likelihood of reporting frequent outdoor mobility. As hypothesised, only some physical limitations (ie, limitations with walking, climbing stairs, carrying and bending) had an independent negative association with going outdoors frequently. Ability to walk and to climb stairs are essential to allow outdoor mobility, whereas limitations with bending and carrying may indicate balance and strength impairments, respectively, that can both negatively influence outdoor mobility. However, when adjusting for sociodemographic, health, psychological and social characteristics in multivariate analyses, only limitations with walking and limitations with climbing stairs remained associated with lower odds of going outdoors frequently. These results suggest that limitations with bending and carrying may be early signs of impending physical limitations, but other risk factors account for their effect on outdoor mobility restriction. Previous studies found that physical limitation with bending was the first physical limitation to be encountered, followed by difficulty with lifting, ${ }^{24}{ }^{25}$ whereas physical limitations with walking and stairs are considered as more severe. ${ }^{26}$ Overall, these results suggest that interventions designed to promote activity and frequent outdoor mobility should also incorporate strength, endurance and balance training to enhance walking.

Another original finding of this study is to highlight that stratifying the analyses by the severity of physical limitations modifies the factors associated with going outdoors frequently. To our knowledge, this has not yet been studied in such details so far. In the present study, most protective factors were no longer significant when restricting the analyses to individuals with severe limitations. In contrast, other variables such as cognitive complaints and urinary incontinence that were not associated with outdoors mobility in the total population or among individuals with mild limitations, did become significant in those with severe limitations. Thus, attempts should be made to better tailor public health interventions to individual's specific physical limitations.

In contrast, depressive feelings significantly decreased the odds of going outdoors frequently in the total population as well as in participants with mild and severe limitations. This highlights the importance to address this issue when promoting outdoor mobility, all the more as depression is common and often underdiagnosed among older adults. ${ }^{27} 28$ This study highlights further reasons to address this issue even if the cross-sectional design of the analysis prevents determining whether depressive symptoms could be a cause or a consequence of restricted outdoor mobility.

When targeting older persons with mild physical limitations, our results suggest that a specific emphasis should be placed on fear of falling. Other studies also observed similar negative associations between fear of falling, mobility and outdoor activity. ${ }^{11}{ }^{29}$ Interventions that effectively address fear of falling, such as exercise, ${ }^{30}$ may be considered in this specific subgroup whereas they might not be a priority target for older people with more pronounced physical limitations.

Indeed, among older people with severe physical limitations, results highlight the potential importance of addressing urinary incontinence as it was associated with significantly lower odds of going outdoors frequently. Previous studies indeed linked incontinence to restricted mobility ${ }^{31}$ or homebound status, ${ }^{32}$ but did not describe whether this association varied according to the severity of physical limitations. These results lend further support to improving the management of urinary incontinence, as well as interventions to better adapt outdoor environment, such as easily accessible public toilets.

Similarly, among individuals with severe limitations, those with cognitive complaints had further decreased odds of reporting frequent outdoor mobility. A potential explanation is that going outdoors with severe physical limitations probably requires significant cognitive resources (use of walking aids, managing breaks, gait, and balance, finding one's way). This result extends previous findings ${ }^{6}$ that also observed this association.

Another significant contribution of the current study is to further highlight the importance of the social dimension as a potential protective factor for frequent outdoor mobility. Results suggest that, besides the living condition, both the quality and the density of the social network may independently play a role. Again, the strength of the association between these social variables and going outdoors frequently varied according to the severity of physical limitations. Indeed, the positive associations of living alone and of a dense social network with going outdoors frequently was observed in the total population as well as in participants with mild limitations, but no longer in those with severe limitations. This observation 
suggests that while these variables might drive individuals without or with only mild physical limitations to go outside, this effect may be lost among those who are more physically disabled. Yet, in this latter group, reporting a new emotional relationship was the only factor associated with increased odds of going outdoors frequently. These findings extend previous results that showed positive association between living alone as well as the frequency of contacts with children residing outside of the home, and improved walking ability. ${ }^{33}$ Overall, these results also lend support for public health interventions aiming at promoting and facilitating socialisation in at-risk elderly people.

\section{Strengths and limitations}

This study has several strengths such as its populationbased sampling with participants being representative ${ }^{34}$ of that population, the large sample included in the analyses allowing for high statistical power, detailed information on the type of physical limitations and on an extensive set of relevant covariates, including different components of social network. This made analyses stratified by the severity of physical limitations possible, thus providing unique information and a more detailed understanding of the interplay between health and social factors that potentially mediate outdoors mobility.

As a limitation, information on MMSE score was missing in 374 (out of 3419) participants. However, results from the sensitivity analyses excluding participants with missing MMSE score did not modify the results within the total sample.

Additional limitations were the cross-sectional design that did not allow to assess causality and the use of selfreported data that might be less reliable than objective measurements.

Finally, the exclusion of subjects with answers by proxy and those with MMSE score below 18 precludes from generalising the findings to older persons with moderateto-severe cognitive impairment.

\section{CONCLUSION}

This study highlights factors that are potentially important in maintaining frequent outdoors mobility (social network), as well as factors likely to threaten it (physical limitations, fear of falling, depressive feelings, cognitive complaints, urinary incontinence). It points to different factors according to the severity of physical limitations and suggests that interventions aiming to promote outdoor mobility and active ageing should be designed accordingly. Further longitudinal studies are needed to establish the direction and causality of observed associations.

Acknowledgements The authors would like to thank all participants in the LC65+ study, as well as the research assistants.

Contributors BSE designed and conducts the LC65+ cohort study. CB, BSE and LSB designed this work. JS, LSB and HK underwent data analysis. JS conducted the literature search and drafted the manuscript. All authors contributed to the interpretation of data, and critically revised the manuscript for important intellectual content. All authors approved the final version for publication.

Funding The authors have not declared a specific grant for this research from any funding agency in the public, commercial or not-for-profit sectors.

Competing interests None declared.

Patient consent for publication Not required.

Ethics approval The Cantonal Human Research Ethical Committee approved the Lausanne Cohort LC65+ initial study protocol (Protocol (19/04), decision letter: 23 February 2004) as well as successive amendments for follow-up. Written informed consent was obtained from all subjects.

Provenance and peer review Not commissioned; externally peer reviewed.

Data availability statement All data relevant to the study are included in the article or uploaded as supplementary information.

Open access This is an open access article distributed in accordance with the Creative Commons Attribution Non Commercial (CC BY-NC 4.0) license, which permits others to distribute, remix, adapt, build upon this work non-commercially, and license their derivative works on different terms, provided the original work is properly cited, appropriate credit is given, any changes made indicated, and the use is non-commercial. See: http://creativecommons.org/licenses/by-nc/4.0/.

ORCID iD

Julia Spaltenstein http://orcid.org/0000-0002-5518-3911

\section{REFERENCES}

1 Harada K, Lee S, Lee S, et al. Objectively-measured outdoor time and physical and psychological function among older adults. Geriatr Gerontol Int 2017;17:1455-62.

2 Harada K, Lee S, Park H, et al. Going outdoors and cognitive function among community-dwelling older adults: Moderating role of physical function. Geriatr Gerontol Int 2016;16:65-73.

3 Kono A, Kai I, Sakato C, et al. Frequency of going outdoors predicts long-range functional change among ambulatory frail elders living at home. Arch Gerontol Geriatr 2007;45:233-42.

4 (WHO), World Health Organization. Active Ageing - A Policy Framework. Madrid, Spain, 2002.

5 Bousquet J, Malva J, Nogues M, et al. Operational definition of active and healthy aging (AHA): the European innovation partnership (EIP) on AHA reference site questionnaire: Montpellier October 20-21, 2014, Lisbon July 2, 2015. J Am Med Dir Assoc 2015;16:1020-6.

6 Petersen J, Austin D, Mattek N, et al. Time out-of-home and cognitive, physical, and emotional wellbeing of older adults: a longitudinal mixed effects model. PLoS One 2015;10:e0139643.

7 Mikkola TM, Polku H, Portegijs E, et al. Self-Reported hearing is associated with time spent out-of-home and withdrawal from leisure activities in older community-dwelling adults. Aging Clin Exp Res 2016;28:297-302.

8 Portegijs E, Rantakokko M, Viljanen A, et al. Perceived and objective entrance-related environmental barriers and daily out-of-home mobility in community-dwelling older people. Arch Gerontol Geriatr 2017;69:69-76.

9 Choi K, Park E, Lee I-S. [Homebound status and related factors according to age in female elders in the community]. J Korean Acad Nurs 2012;42:291-301.

10 Kanzaki-Sooudi K. The relationship between time spent outdoors, falls, and fall-risk among the community-dwelling elderly in rural Japan. Home Healthc Nurse 2009;27:570-7.

11 Smith AR, Chen C, Clarke P, et al. Trajectories of outdoor mobility in vulnerable community-dwelling elderly: the role of individual and environmental factors. J Aging Health 2016;28:796-811.

12 Lêng $\mathrm{CH}$, Wang J-D. Long term determinants of functional decline of mobility: an 11-year follow-up of 5464 adults of late middle aged and elderly. Arch Gerontol Geriatr 2013;57:215-20.

13 Guzman-Castillo M, Ahmadi-Abhari S, Bandosz P, et al. Forecasted trends in disability and life expectancy in England and Wales up to 2025: a modelling study. Lancet Public Health 2017;2:e307-13.

14 Musich S, Wang SS, Ruiz J, et al. The impact of mobility limitations on health outcomes among older adults. Geriatr Nurs 2018;39:162-9.

15 Kestens Y, Chaix B, Gerber P, et al. Understanding the role of contrasting urban contexts in healthy aging: an international cohort study using wearable sensor devices (the CURHA study protocol). BMC Geriatr 2016;16:96.

16 Levasseur M, Généreux M, Bruneau J-F, et al. Importance of proximity to resources, social support, transportation and neighborhood security for mobility and social participation in 
older adults: results from a scoping study. BMC Public Health 2015;15:503.

17 Marquet O, Miralles-Guasch C. Neighbourhood vitality and physical activity among the elderly: the role of walkable environments on active ageing in Barcelona, Spain. Soc Sci Med 2015;135:24-30.

18 Ornstein KA, Leff B, Covinsky KE, et al. Epidemiology of the Homebound population in the United States. JAMA Intern Med 2015;175:1180-6.

19 Musich S, Wang SS, Hawkins K, et al. Homebound older adults: prevalence, characteristics, health care utilization and quality of care. Geriatr Nurs 2015;36:445-50.

20 De-Rosende Celeiro I, Santos-Del-Riego S, Muñiz García J. Homebound status among middle-aged and older adults with disabilities in ADLs and its associations with clinical, functional, and environmental factors. Disabil Health J 2017; 10:145-51.

21 Soones T, Federman A, Leff B, et al. Two-Year mortality in Homebound older adults: an analysis of the National health and aging trends study. J Am Geriatr Soc 2017;65:123-9.

22 Hamazaki Y, Morikawa Y, Morimoto S, et al. Difference in the impact of homebound status on functional decline between independent older men and women: a 2 year follow-up study. Jpn J Nurs Sci 2016;13:265-75.

23 Santos-Eggimann B, Karmaniola A, Seematter-Bagnoud L, et al. The Lausanne cohort Lc65+: a population-based prospective study of the manifestations, determinants and outcomes of frailty. BMC Geriatr 2008;8:20.

24 Kingston A, Collerton J, Davies K, et al. Losing the ability in activities of daily living in the oldest old: a hierarchic disability scale from the Newcastle 85+ study. PLoS One 2012;7:e31665.
25 Bendayan R, Cooper R, Wloch EG, et al. Hierarchy and speed of loss in physical functioning: a comparison across older U.S. and English men and women. J Gerontol A Biol Sci Med Sci 2017;72:1117-22.

26 Chen $\mathrm{H}-\mathrm{Y}$, Wang C-Y, Lee M-Y, et al. A hierarchical categorisation of tasks in mobility disability. Disabil Rehabil 2010;32:1586-93.

27 Padayachey U, Ramlall S, Chipps J. Depression in older adults: prevalence and risk factors in a primary health care sample. South African Family Practice 2017;59:61-6.

28 Wang J, Wu X, Lai W, et al. Prevalence of depression and depressive symptoms among outpatients: a systematic review and metaanalysis. BMJ Open 2017;7:e017173.

29 Paraschiv-lonescu A, Büla CJ, Major K, et al. Concern about falling and complexity of free-living physical activity patterns in WellFunctioning older adults. Gerontology 2018;64:603-11.

30 Kendrick D, Kumar A, Carpenter H, et al. Exercise for reducing fear of falling in older people living in the community. Cochrane Database Syst Rev 2014;11:CD009848.

31 Suhr R, Lahmann NA. Urinary incontinence in home care: a representative multicenter study on prevalence, severity, impact on quality of life, and risk factors. Aging Clin Exp Res 2018;30:589-94.

32 McDowell BJ, Engberg SJ, Rodriguez E, et al. Characteristics of urinary incontinence in homebound older adults. J Am Geriatr Soc 1996;44:963-8.

33 Litwin H, Stoeckel KJ. Social network and mobility improvement among older Europeans: the ambiguous role of family ties. Eur $J$ Ageing 2013:10:159-69.

34 Representativeness | Lausanne cohorte 65+ [Internet]. Available: https://lc65plus.iumsp.ch/en/content/representativeness [Accessed cited 2020 Mar 14]. 